\title{
Prognostic value of proliferation assay in the luminal, HER2-positive, and triple-negative biologic classes of breast cancer
}

\author{
Mohammed A Aleskandarany ${ }^{1,2}$, Andrew R Green ${ }^{1}$, Ahmed A Benhasouna', Fabricio F Barros ${ }^{1}$, Keith Neal ${ }^{3}$, \\ Jorge S Reis-Filho ${ }^{4}$, lan $\mathrm{O}$ Ellis $^{1}$ and Emad A Rakha ${ }^{1 *}$
}

\begin{abstract}
Introduction: Although the prognostic significance of proliferation in early invasive breast cancer has been recognized for a long time, recent gene-expression profiling studies have reemphasized its biologic and prognostic value and the potential application of its assessment in routine practice, particularly to define prognostic subgroups of luminal/hormone receptor-positive $\left(\mathrm{HR}^{+}\right)$tumors. This study aimed to assess the prognostic value of a proliferation assay by using Ki-67 immunohistochemistry as compared with mitotic count scores.
\end{abstract}

Method: Proliferation was assessed by using Ki-67 labeling index (Ki-67LI) and mitotic scores in a large $(n=1,550)$ and well-characterized series of clinically annotated primary operable invasive breast cancer with long-term followup. Tumors were phenotyped based on their $\mathrm{IHC}$ profiles into luminal/HR ${ }^{+}, \mathrm{HER} 2^{+}$, and triple-negative (TN) classes. We used a split-sample development and validation approach to determine the optimal Ki-67LI cut-offs.

Results: The optimal cut-points of Ki-67LI were $10 \%$ and 50\% for the luminal class. Both Ki $7 \mathrm{LI}$ and MS were able to split luminal tumors into subgroups with significantly variable outcomes, independent of other variables. Neither mitotic count scores nor Ki-67LI was associated with outcome in the HER2 ${ }^{+}$or the TN classes.

Conclusions: Assessment of proliferation by using Ki-67LI and MS can distinguish subgroups of patients within luminal/hormone receptor-positive breast cancer significantly different in clinical outcomes. Overall, both Ki-67 LI and mitotic-count scores showed comparable results. The method described could provide a cost-effective method for prognostic subclassification of luminal/hormone receptor-positive breast cancer in routine clinical practice.

\section{Introduction}

Tumor proliferative activity represents one of the most thoroughly investigated cellular functions in breast cancer $(B C)$ for its association with tumor behavior [1]. Assessment of proliferation rates has been shown to provide useful information on prognosis and aggressiveness of individual cancers and can potentially be used to guide treatment protocols in clinical practice. Recently, a meta-analysis of publicly available breast cancer geneexpression signatures has identified proliferation as the key biologic driver in all nine prognostic signatures included in the study [2]. It was also demonstrated that

\footnotetext{
* Correspondence: emadrakha@yahoo.com

'Department of Histopathology, School of Molecular Medical Sciences, Queens Medical Centre, University of Nottingham and Nottingham University Hospitals NHS Trust, Nottingham, NG7 2UH, UK Full list of author information is available at the end of the article
}

the assignment of basal-like and ERBB2 ${ }^{+}\left(\mathrm{HER}^{+}\right)$breast cancers to the poor-prognosis groups by first-generation gene signatures is determined mainly by high expressions of proliferation-related genes [2,3]. Moreover, it has been reported that expression of genes involved in cell proliferation is the most heavily weighted component in calculating the recurrence score [4] and is the basis of genomic grading $[5,6]$.

Various techniques have been developed to quantify proliferation rates, including, mitotic-count estimates, measurement of DNA synthesis, and flow cytometry [1,7-9]. Newer techniques include detection of antigens closely associated with proliferation by using immunohistochemistry (IHC). In theory, the latter methods are quicker, cheaper, and easier to use than flow cytometry and autoradiography and are more reproducible than is

\section{Biomed Central}

(c) 2011 Alekandarany et al.; licensee BioMed Central Ltd. This is an open access article distributed under the terms of the Creative Commons Attribution License (http://creativecommons.org/licenses/by/2.0), which permits unrestricted use, distribution, and reproduction in any medium, provided the original work is properly cited. 
mitotic figure counting [7]. Although most studies of different proliferation assays displayed significant agreement in outcome predictions for individual patients, no consensus exists on the best proliferation assay [10]. Mitotic-count scores (MSs) are used in routine BC histologic grading, and the prognostic significance is well established [11,12]. Immunohistochemical expression of Ki-67 is now widely used as an IHC measure of proliferation [13-15]. Although Ki-67 is not yet incorporated into routine pathology practice, its use in proliferation assays in translational studies has yielded promising results [16-18]. Several studies have sub-classified luminal tumors (that is, estrogen receptor (ER)-positive, HER2 negative) based on differential expression of proliferation-associated genes "proliferation signature," gene-expression profiling (GEP), or by Ki-67 in IHC studies $[16,17,19]$. However, some technical and validation issues are to be addressed before $\mathrm{Ki}-67$ is used in BC routine practice. It remains to be determined whether Ki-67 IHC outperforms mitotic counting as a predictor of outcome. Moreover, evidence of the prognostic value of using MS in an algorithm for defining molecular BC classes is yet to be elucidated.

Consequently, this study was conducted on a large, well-characterized series of early (stage I through III) invasive $\mathrm{BC}$ with long-term follow-up to study the prognostic value of MS and Ki-67LI, as methods of proliferation assays, in different $\mathrm{BC}$ molecular classes. We used a split-sample development and validation approach to determine the optimal Ki-67LI cut-offs and demonstrated its prognostic relevance in the validation cohort in luminal/ $/ \mathrm{HR}^{+}, \mathrm{HER}^{+}$, and triple-negative tumors.

\section{Materials and methods}

\section{Patients and tumors}

This study was based on a well-characterized cohort of early-stage (I-III) primary operable invasive BC from patients aged 70 years or younger, enrolled into the Nottingham Tenovus Primary Breast Carcinoma Series between 1990 and $1998(n=1,550)$, and managed in accordance with a uniform protocol. Patients' clinical history, tumor characteristics, and information on therapy and outcomes are prospectively maintained. Outcome data include survival status, survival time, cause of death, development, and time to locoregional recurrence and distant metastasis (DM). Breast Cancer Specific Survival (BCSS) is defined as the time (in months) from the date of primary surgery to the date of breast cancerrelated death. DMFS is defined as the time (in months) from the date of primary surgery to the appearance of distant metastasis.

Patients had a median age of 54 years (range, 18 to 70 years) with a median overall survival of 123 months (range, 4 to 234 months) and a median time of event- free survival of 110 months (range, 3 to 226 months). Distant recurrence occurred in 443 (30.4\%) cases; 392 (26.9\%) patients died of BC; and 747 (58.1\%) patients were alive at the end of follow-up.

\section{Assessment of mitotic counts}

Mitotic figures were counted by one of three pathologists with extensive experience in BC histopathology from Nottingham City Hospital, Nottingham, UK (Ian Ellis, Sarah Pinder, and Christopher Elston), in 10 highpower fields, as part of routine $\mathrm{BC}$ histologic grading [20]. Scores of 1 to 3 were used, with cut-off points determined based on association with outcome (MS 1, $\leq$ 9 mitoses/10 hpf; MS 2, 10 to 19 mitoses/10 hpf; and MS 3, $\geq 20$ mitoses/10 hpf) by using a $0.59-\mathrm{mm}$ microscopic field diameter [21].

\section{Ki-67 immunohistochemistry}

Formalin-fixed paraffin tissue sections (FFSs, $4 \mu \mathrm{m}$ ) mounted on Superfrost slides (Surgipath) were immunohistochemically stained, by using the standard streptavidin-biotin complex method, as previously described [22]. Microwave-assisted heat-induced retrieval method for antigen epitopes was performed in citrate buffer, at $\mathrm{pH} 6.0$ for 20 minutes. Endogenous peroxidase activity was blocked by incubation in a $0.3 \%$ hydrogen peroxide in methanol buffer for 10 minutes. Nonspecific binding of primary antibody was blocked by using normal swine serum (NSS, in Tris-buffered saline (TBS) (1:5), $100 \mu \mathrm{l} /$ slide) for 10 minutes of incubation. Primary mouse monoclonal anti-Ki-67 antibody (MIB1 clone, product M7240; Dako, Glostrup, Denmark), diluted 1:100 (optimum working dilution) in NSS/TBS, was applied to each slide and incubated for 60 minutes at room temperature. Slides were then rinsed in TBS before staining with a streptavidin-biotin three-stage technique, with the Dako Strept ABC complex/HRP Duet kit (Dako, K492) according to manufacturer's guidelines. For reaction visualization, 3-3 diaminobenzidine tetrahydrochloride (Dako liquid DAB Plus, K3468) was used as chromogen. The sections were counterstained with Mayer hematoxylin (Dako, AR106). Human tonsil sections were used as positive control, whereas negative control was performed by replacing the primary antibody by TBS. These controls were included in each staining run. Additionally, to assess the optimal number of tumor blocks from an individual case sufficient to report on Ki-67LI, four FFSs cut from four different paraffin blocks, representative of 25 invasive $\mathrm{BC}$ cases, also were stained.

\section{Ki67 scoring}

Immunostaining was quantitatively evaluated by using light microscopy, in which the entire section was scanned at low-power magnification $(\times 100)$ to 
determine areas with the highest numbers of positive nuclei (hot spot) within the invasive component [22]. These were usually found at the periphery of tumors and were easier to identify than the mitotic figure hot spots. Ki-67 labeling index (Ki-67LI) was expressed as the percentage of MIB1-positive cells among a total number of 1,000 malignant cells at high-power magnification $(\times 400)$. A randomly chosen subset of cases $(n=$ 200) was rescored by the same observer (MA), and an intraobserver reproducibility test was performed (kappa value, 0.85$)$.

\section{Definition of molecular classes}

Data on a wide range of biomarkers of known clinical and biologic relevance to $\mathrm{BC}$ were available, including hormone receptors $[\mathrm{HR}, \mathrm{ER}$, and progesterone receptor (PR)], epidermal growth factor-receptor family members (HER1 (EGFR), and HER2) and basal cytokeratins (CKs) (CK5/6 and CK14) [23,24]. In this study, HER2 was assessed by using IHC and dual-color chromogenic in situ hybridization (CISH), as previously published [25]. Moreover, data on a subset of 128 frozen $\mathrm{BC}$ tissues that were profiled by using Illumina WG-6 BeadChips, as previously described [26], was available. These expression data are available at the EBI website http://www.ebi.ac. uk/miamexpress/ with E-TABM-576 accession number.

Molecular classes were defined as luminal $\left(\mathrm{HR}^{+}: \mathrm{ER}^{+}\right.$ and/or $\left.\left.\mathrm{PR}^{+}\right]\right)$, HER2 ${ }^{+}\left(\mathrm{HER} 2^{+}\right.$regardless of the expression of other markers), basal-like [BLBC] $\left(\mathrm{ER}^{-}, \mathrm{PR}^{-}\right.$, HER2 ${ }^{-}$, and positive for CK5/6, and/or CK14 and/or EGFR), and triple-negative nonbasal BC (TNnon-B; all these markers negative) [23,27].

To assess the optimal Ki-67 LI cut-off in different molecular classes and to avoid data overfitting, each molecular class was randomly split into two subsets by using SPSS random sampling; one third of cases were used as a training set, and the remaining two thirds used as a validation (test) set. No differences between training and validation sets were identified in any of the molecular classes (Table 1).

Table 1 Clinicopathologic features of the whole

\begin{tabular}{|c|c|c|c|c|c|c|c|c|c|c|}
\hline \multirow[t]{2}{*}{ Characteristics } & \multirow[t]{2}{*}{ Whole series } & \multicolumn{3}{|c|}{ Luminal class } & \multicolumn{3}{|c|}{$\mathrm{HER}^{+}{ }^{+}$class } & \multicolumn{3}{|c|}{ Triple-negative class } \\
\hline & & $\begin{array}{l}\text { Training } \\
\text { No (\%) }\end{array}$ & $\begin{array}{l}\text { Validation } \\
\text { No }(\%)\end{array}$ & $P$ & $\begin{array}{l}\text { Training } \\
\text { No (\%) }\end{array}$ & $\begin{array}{l}\text { Validation } \\
\text { No (\%) }\end{array}$ & $P$ & $\begin{array}{l}\text { Training } \\
\text { No (\%) }\end{array}$ & $\begin{array}{l}\text { Validation } \\
\text { No (\%) }\end{array}$ & $P$ \\
\hline \multicolumn{11}{|l|}{ Age } \\
\hline Median (Range) & $54(18-70)$ & $55(18-70)$ & $55(28-70)$ & 0.690 & $52(29-69)$ & $52(27-70)$ & 0.657 & 49.5 (29-70) & $50(27-70)$ & 0.885 \\
\hline \multicolumn{11}{|l|}{ Menopausal status } \\
\hline Premenopausal & $571(39.2)$ & $116(36.7)$ & $232(35.6)$ & 0.887 & $31(47.7)$ & $58(45.3)$ & & $44(54.8)$ & $90(56.3)$ & 0.892 \\
\hline Postmenopausal & $886(60.8)$ & $200(63.3)$ & $419(64.4)$ & & $34(52.3)$ & $70(57.7)$ & 0.762 & $36(45.1)$ & $70(34.8)$ & \\
\hline \multicolumn{11}{|l|}{ Tumor grade } \\
\hline Grade I & $255(17.5)$ & $80(25.3)$ & $151(23.2)$ & & $2(3.1)$ & $5(3.9)$ & & $3(3.6)$ & $1(0.6)$ & 0.892 \\
\hline Grade ॥ & $479(32.9)$ & $141(43.9)$ & $282(43.3)$ & 0.371 & $8(12.3)$ & $25(19.5)$ & 0.417 & $7(8.3)$ & $8(5.0)$ & \\
\hline Grade III & $723(48.6)$ & 95 (29.6) & $218(33.5)$ & & $55(84.6)$ & 98 (76.6) & & $70(88.1)$ & $151(94.4)$ & \\
\hline \multicolumn{11}{|l|}{ Tumor size } \\
\hline$\leq 2 \mathrm{~cm}$ & $899(61.8)$ & $215(68.1)$ & $433(66.5)$ & 0.561 & $40(61.5)$ & $77(60.2)$ & 0.877 & $42(52.5)$ & $71(44.4)$ & 0.180 \\
\hline$>2 \mathrm{~cm}$ & $556(38.2)$ & $101(31.9)$ & $218(33.5)$ & & $25(38.5)$ & $51(39.8)$ & & $38(47.5)$ & 89 (55.6) & \\
\hline \multicolumn{11}{|l|}{ Tumor type } \\
\hline Ductal, no special type & $853(58.5)$ & $159(50.3)$ & $331(50.8)$ & 0.874 & $59(90.8)$ & $112(88.2)$ & 0.807 & $70(87.5)$ & $136(86.1)$ & 1.00 \\
\hline Other histologic types & $604(41.5)$ & $157(49.7)$ & $320(49.2)$ & & $6(9.2)$ & $15(11.8)$ & & $12(12.5)$ & $22(13.9)$ & \\
\hline \multicolumn{11}{|l|}{$\mathrm{NPI}^{\mathrm{a}}$} \\
\hline Good & $457(31.4)$ & $141(44.6)$ & $275(42.2)$ & & $4(6.5)$ & $16(12.5)$ & & $7(8.6)$ & $13(8.1)$ & \\
\hline Moderate & $767(52.6)$ & $145(45.9)$ & $295(45.3)$ & 0.312 & $47(72.3)$ & $78(60.9)$ & 0.226 & $55(68.9)$ & $109(68.1)$ & 0.417 \\
\hline Poor & $233(16.0)$ & $30(9.5)$ & $81(12.4)$ & & $14(21.5)$ & $34(26.6)$ & & $18(22.5)$ & $38(23.8)$ & \\
\hline Mean (range) & $3.4(2.04-5)$ & $3.42(2.05-5)$ & $3.43(2.06-5)$ & & $4.7(2.6-5)$ & $4.7(2.6-5)$ & & $4.51(2.05-5)$ & $4.52(2.05-5)$ & \\
\hline \multicolumn{11}{|l|}{ Recurrence } \\
\hline Local: No & $1,249(89.0)$ & 283 (89.6) & $588(90.3)$ & & 55 (84.6) & $108(84.4)$ & & $70(87.5)$ & $136(85.0)$ & 0.564 \\
\hline Yes & $160(11.0)$ & 33 (10.4) & $63(9.7)$ & 0.819 & 10 (15.4) & $20(15.6)$ & 1.000 & $10(12.5)$ & $24(15.0)$ & \\
\hline Regional: No & $1,280(91.0)$ & $291(92.1)$ & $594(91.2)$ & & $58(89.2)$ & $112(87.5)$ & & $70(87.5)$ & 147 (91.9) & 0.259 \\
\hline Yes & $129(9.0)$ & $25(7.9)$ & $57(8.8)$ & 0.713 & 7 (10.8) & $16(12.5)$ & 0.817 & $10(12.5)$ & $13(8.1)$ & \\
\hline Distant: No & $1,014(69.6)$ & 239 (75.6) & $473(72.7)$ & 0.278 & $34(52.3)$ & $71(55.5)$ & & $50(62.5)$ & 107 (66.9) & 0.573 \\
\hline Yes & $443(30.4)$ & $77(24.4)$ & $178(27.3)$ & & $31(47.7)$ & $57(44.5)$ & 0.760 & $30(37.5)$ & $53(33.1)$ & \\
\hline
\end{tabular}

${ }^{\text {a Series }}(n=1,457)$, training sets, and validation sets of luminal, HER2 ${ }^{+}(n=193)$, and TN $(n=244)$ molecular BC classes Nottingham Prognostic Index. Good Prognostic Group, $\leq 3.4$; Moderate Prognostic Group, 3.41 to 5.4, Poor Prognostic Group, > 5.4 


\section{Statistical analysis}

Statistical analysis was performed by using SPSS 15.0 statistical package (SPSS Inc., Chicago, IL, USA). X-tile software (version 3.6.1, 2003-2005, Yale University, New Haven, CT, USA) [28] was used to de-termine the optimal Ki-67LI cutoff point(s) in different molecular subtypes. Correlations between Ki-67LI and MS and other variables were studied with a $\chi^{2}$ test, Fisher Exact test, and Mann-Whitney $U$ test. Survival curves for BCSS and DMFS were drawn by using the Kaplan-Meier estimates, and significance was assessed by using log-rank tests. Multivariate analyses of BCSS and DMFS were conducted by using Cox proportional hazard regression models. A two-tailed $P$ value $<0.05$ was considered significant.

This study was approved by the Nottingham Research Ethics Committee 2 under the title "Development of a molecular genetic classification of breast cancer." All patients who participated in this study gave their written informed consent at the time of their donation.

\section{Results}

In the current study, informative results for Ki-67LI, MS, and follow-up data were available for 1,457 cases ( $94 \%$ of the whole series). To assess the optimal number of FFSs sufficient to report Ki-67LI reliably, four FFSs were cut from four different paraffin blocks representative of 25 invasive $\mathrm{BC}$ cases. These showed high levels of concordance between sections when Ki-67LI was analyzed as continuous variable $(P<0.0001$; Table 2$)$ and when categorized by using different cut-off points (kappa value, $0.834 ; 95 \% \mathrm{CI}, 0.76$ to 0.92 ), indicating that one FFS is sufficient for reliable Ki-67LI assessment.

Significant association was observed between Ki-67LI and MKI67 gene transcript, as defined by microarraybased gene-expression profiling $\left(r^{2}=0.24 ; P<0.0001\right)$, and between Ki-67LI and MS $(P<0.0001)$. High Ki67LI and MS were associated with premenopausal status, larger tumor size, definite vascular invasion, and lymph node involvement $(P<0.0001)$. Significant differences appeared between $\mathrm{BC}$ molecular classes regarding their Ki-67LI (ANOVA, $F=167 ; P<0.0001$ ) (Figure 1). Bonferroni post hoc testing of $\mathrm{Ki}-67 \mathrm{LI}$ revealed significant differences between luminal (lowest Ki-67LI) and HER2 ${ }^{+}$(intermediate Ki-67LI) and between HER2 ${ }^{+}$ and triple-negative (highest Ki-67LI) classes. However, the difference between BLBC and TNnon-B was not significant $(P=0.263)$. Similar results were found when MS was used to define proliferation. When the prognostic results of Ki-67LI were expressed as a continuous variable in the class of luminal ER ${ }^{+} / \mathrm{HER} 2^{-}$tumors, this showed association with outcome $\left(\chi^{2}=80 ; P<0.0001\right.$; $\mathrm{HR}=1.1 ; 95 \% \mathrm{CI}, 1.0$ to 1.2$)$. Moreover, Ki-67LI cutoffs at $10 \%$ increments within the same class showed statistically significant differences between the resulting patients' subsets $(\mathrm{LR}=142.64 ; P<0.0001 ; \mathrm{HR}=1.3$; $95 \% \mathrm{CI}=1.2$ to 1.3 ; Figure 2 ).

\section{Determination of the optimal Ki-67LI cut-offs}

In the training sets, the prognostic significance of previously defined Ki-67LI cut-off points including 10\%, 13\%, 17\% (median), 20\%, 25\%, 30\%, 35\% [16,27,29,30] were assessed (Table 3 ). This shows that $10 \%$ cut-off had the highest hazard ratios in the luminal class, but none of these cut-offs was statistically significant in HER2 $^{+}$or TN classes. The optimal Ki-67LI cut-offs within each molecular class was then assessed by using $\mathrm{X}$-tile software analysis [28]. In the luminal class, this showed that $10 \%$ is the optimal cut-off separating low from moderate/high proliferative subgroups. In addition, it showed that $50 \%$ cut-off value can split the latter subgroup into two prognostically different subclasses (moderate $(10 \%$ to $50 \%)$ and high proliferative subgroups (> $50 \%)$ ) with a reasonable number of cases within each subclass (Figure 3 ). In HER $2^{+}$and TN classes, only one cut-off could be identified ( $75 \%$ and $70 \%$, respectively). Table 4 displays MS, training and validation sets, and Ki-67LI cut-off points in BC molecular classes.

\section{Proliferation in luminal class}

Univariate survival analysis of the validation set revealed significant association between MS (1,2, and 3) and patients' outcomes, including BCSS $(P<0.001, \mathrm{HR}=2.3$; 95\% CI $=1.9$ to 2.8$)$, and DMFS $(P<0.001 ; \mathrm{HR}=1.9 ; 95 \%$ CI, 1.6 to 2.3). Low, moderate, and high proliferative subgroups of luminal class validation set displayed significant

Table 2 Results of multivariate analysis of variance (MANOVA) test for Ki-67LI assessed on FFS from 25 invasive BC cases

\begin{tabular}{lllll}
\hline Factor & Mean Ki-67LI & Standard error & \multicolumn{2}{l}{ 95\% confidence interval } \\
& & & Lower bound & Upper bound \\
\hline Section 1 & 71.280 & 4.701 & 62.376 & 81.184 \\
Section 2 & 74.800 & 4.034 & 66.475 & 83.125 \\
Section 3 & 71.800 & 4.709 & 62.082 & 81.518 \\
Section 4 & 74.160 & 4.054 & 65.793 & 82.527 \\
\hline
\end{tabular}

Presented as one section per block; four sections per case. 


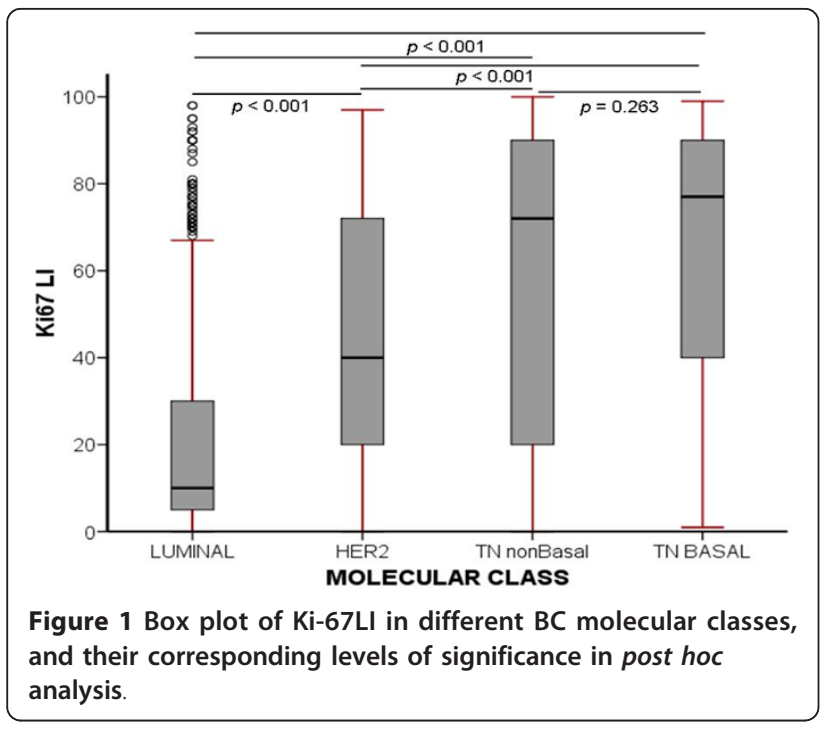

differences in BCSS ( $\mathrm{LR}=76.75 ; P<0.001 ; \mathrm{HR}=2.5 ; 95 \%$ CI, 2.0 to 3.2) and DMFS (LR $=90.87 ; P<0.001 ; \mathrm{HR}=$ 2.2; $95 \%$ CI, 1.8 to 2.7 ) (Figure 4). Multivariate analysis showed that both MS and Ki-67LI were independent prognostic factors $(P<0.001)$. However, the HR for Ki-67LI was slightly higher than that of MS, although the CIs of the high-proliferation subgroups overlapped. As Ki-67LI and MS are highly correlated, multivariate analysis including MS, tumor grade, nodal stage, and tumor size was repeated after the addition of Ki-67LI. This showed that Ki-67LI has a higher HR than that of MS for both BCSS and DMFS; Table 5.

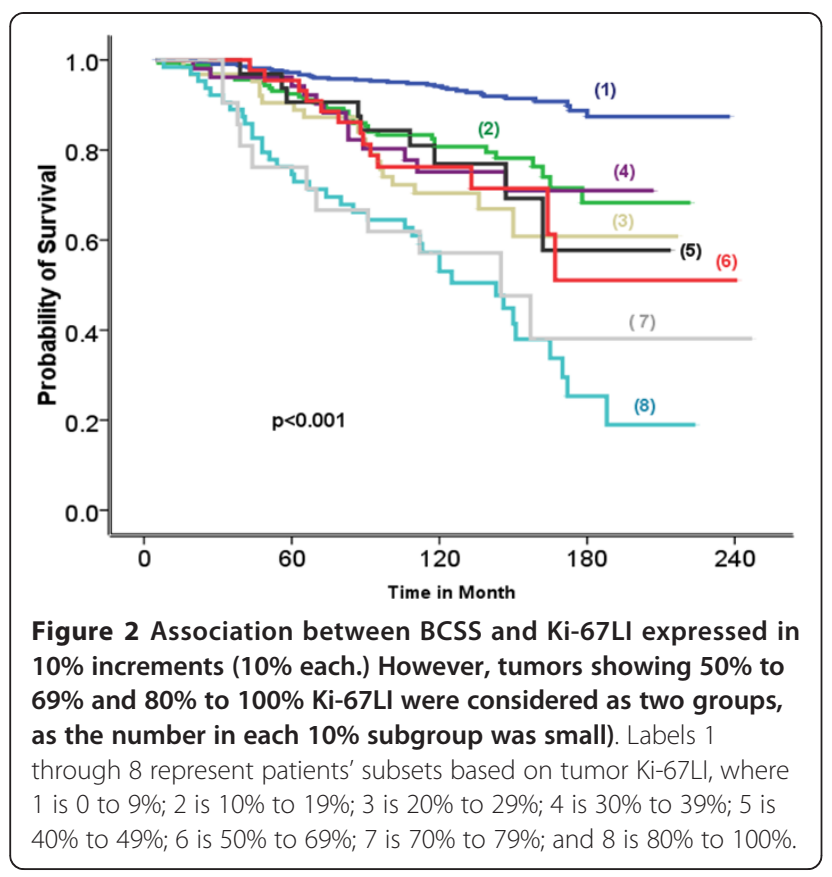

Interestingly, the HRs for both BCSS and DMFS were highest for Ki-67LI, followed by histologic grade, HER2 status, and then by MS, whereas the lowest HR was achieved by PR status; Table 6 .

To assess the difference between Ki-67 and HER2 status in $\mathrm{HR}^{+}$cancers, luminal tumors were further classified after inclusion of $\mathrm{HR}^{+} / \mathrm{HER} 2^{+}$tumors [31,32] into luminal 1 and 2, with the former being $\mathrm{HR}^{+}$and HER2 ${ }^{-}$ (luminal), and the later being $\mathrm{HR}^{+}$and $\mathrm{HER}^{+}$. In luminal 1 subclass, both Ki-67LI and MS were associated with BCSS and DMFS, independent of other variables. However, no associations were found between either MS or Ki-67LI with BCSS or DMFS in luminal 2 subclass by using either $10 \%$ and $50 \%$ or $75 \% \mathrm{Ki}-67 \mathrm{LI}$ cutoffs. When HER2 status and proliferation were considered within $\mathrm{HR}^{+}$tumors, distinct subclasses with prognostic significance were identified (Figure 5). Ki-67LI and MS classified $\mathrm{HR}^{+}$tumors into low (excellent outcome) and moderate proliferative activity (moderately poor outcome), whereas the high-proliferative group was associated with the worst outcome that was not different from HER2 ${ }^{+}$tumors (Table 7 ). Similar results were obtained after adjustment for chemotherapy. Multivariate analysis including size, nodal stage, VI, systemic therapy, Ki-67LI, and MS showed that Ki-67LI HR (1.6; $95 \% \mathrm{CI}, 1.2$ to 2.1$)$ is similar to that of stage $(1.8 ; 95 \%$ CI, 1.4 to 2.2 ) and HER2 (1.7; 95\% CI, 1.3 to 2.6 ), and higher than that of MS $(1.4 ; 95 \% \mathrm{CI}, 1.1$ to 1.8$)$.

In addition, analysis of 70 luminal tumors defined by global gene-expression profiling [26] showed significant association between Ki-67LI and BCSS $(P=0.011$; HR, 2.2; 95\% CI, 1.2 to 4.1$)$ and DMFS $(P=0.016$; HR, 2.1; 95\% CI, 1.1 to 3.7$)$, and between MS and BCSS ( $P=$ 0.024; HR, $1.8 ; 95 \% \mathrm{CI}, 1.1$ to 3.1$)$ and DMFS $(P=$ 0.015 ; HR, 1.9 ; $95 \% \mathrm{CI}, 1.1$ to 3.2 ).

\section{Proliferation in HER2-positive breast cancer}

Kaplan-Meier plots showed no association between MS and either BCSS $(P=0.611 ; \mathrm{HR}, 1.1 ; 95 \% \mathrm{CI}, 0.7$ to 1.5$)$ or DMFS ( $P=0.617$; HR, $1.0 ; 95 \% \mathrm{CI}, 0.7$ to 1.5$)$ in $\mathrm{HER}^{+}$tumors. Combining MS1 and 2 and repeated testing against MS3 yielded the same results. Although 75\% Ki-67LI cut-off split the HER2 ${ }^{+}$training set into low/ moderate $(<75 \%$; $80 \%$ of cases) and high-proliferative $(\geq$ $75 \%$; $20 \%$ of cases) subclasses with difference in outcomes, survival analysis within the HER $2^{+}$validation set showed no significant difference between these two subgroups for either BCSS $(P=0.445)$ or DMFS $(P=0.784)$.

\section{Proliferation in triple-negative breast cancers}

Univariate survival analysis revealed no association between MS and either BCSS $(P=0.317)$ or DMFS $(P=0.590)$ in TN cancers. Similarly, no difference was found when MS1 and 2 were combined and tested against MS3. In addition, 
Table 3 Hazard ratios for different Ki-67LI cut-off points for BCSS and DMFS in luminal and HER ${ }^{+}$training sets

\begin{tabular}{|c|c|c|c|c|c|c|c|c|}
\hline \multirow[t]{3}{*}{ Cut-off point } & \multicolumn{4}{|c|}{ Luminal BC } & \multicolumn{4}{|c|}{ HER2 $^{+}$BC } \\
\hline & \multicolumn{2}{|c|}{ BCSS } & \multicolumn{2}{|l|}{ DMFS } & \multicolumn{2}{|c|}{ BCSS } & \multicolumn{2}{|l|}{ DMFS } \\
\hline & $P$ & HR $(95 \% \mathrm{Cl})$ & $P$ & HR $(95 \% \mathrm{Cl})$ & $P$ & HR $(95 \% \mathrm{Cl})$ & $P$ & HR $(95 \% \mathrm{Cl})$ \\
\hline $10 \%$ & $<0.001$ & $4.289(3.043-6.045)$ & $<0.001$ & $2.951(2.233-3.901)$ & 0.439 & $1.314(0.658-2.625)$ & 0.401 & $1.334(0.674-2.682)$ \\
\hline $13 \%$ & & $3.484(2.580-4.704)$ & & $2.595(2.006-3.356)$ & 0.647 & $0.883(0.519-1.503)$ & 0.758 & $0.920(0.541-1.536)$ \\
\hline $17 \%$ & & $3.387(2.547-4.506)$ & & $2.468(1.923-3.166)$ & 0.318 & $0.780(0.480-1.270)$ & 0.368 & $0.800(0.493-1.299)$ \\
\hline $20 \%$ & & $3.555(2.683-4.712)$ & & $2.578(2.012-3.304)$ & 0.367 & $0.805(0.502-1.291)$ & 0.457 & $0.837(0.523-1.339)$ \\
\hline $25 \%$ & & $3.091(2.348-4.069)$ & & $2.458(1.918-3.150)$ & 0.355 & $0.810(0.519-1.265)$ & 0.483 & $0.854(0.549-1.328)$ \\
\hline $30 \%$ & & $3.004(2.283-3.954)$ & & $2.415(1.880-3.101)$ & 0.717 & $0.923(0.596-1.427)$ & 0.824 & $0.952(0.617-1.468)$ \\
\hline $35 \%$ & & $3.182(2.413-4.195)$ & & $2.648(2.055-3.413)$ & 0.698 & $1.089(0.708-1.675)$ & 0.723 & $1.080(0.706-1.652)$ \\
\hline $10 \%$ and $50 \%$ : & & & & & 0.191 & & 0.334 & \\
\hline Moderate vs. low & & $3.473(2.421-4.983)$ & & $2.483(1.847-3.336)$ & 0.747 & $1.126(0.547-2.319)$ & 0.611 & $1.205(0.588-2.469)$ \\
\hline High vs. low & & $7.648(5.116-11.43)$ & & $5.021(3.533-7.134)$ & 0.188 & $1.638(0.786-3.414)$ & 0.220 & $1.586(0.759-3.313)$ \\
\hline
\end{tabular}

BCSS, Breast cancer-specific survival; DMFS, distant metastasis-free survival; MS, mitosis score.

no association was found between Ki-67LI and BCSS or DMFS by using the $\mathrm{X}$-tile generated cut-point in the TN $\mathrm{BC}$ training set (that is, $70 \% ; P=0.174$ ). When $\mathrm{TN}$ tumors were subclassified into BLBC and TNnon-B BC, KaplanMeier plots showed no significant association between MS and Ki-67I and either BCSS or DMFS $(P>0.05)$.

\section{Discussion}

Although the prognostic significance of proliferation in $\mathrm{BC}$ has been documented and validated in several independent studies, recent global gene-expression profiling studies have reemphasised its biologic and prognostic importance. Several studies have identified the proliferation signature as a key element in the molecular classification of $\mathrm{BC}$ and in the composition of different prognostic and predictive gene signatures [2]. Therefore, some recent studies have raised the issue of using an immunohistochemical marker for assessment of proliferation (for example, Ki-67) to be used in combination with other IHC surrogate panels used for BC molecular classification: ER, PR, and HER2 $[16,17]$. These studies have demonstrated that $\mathrm{Ki}-67 \mathrm{LI}$ is associated with outcome and, when used in combination with other markers mentioned previously,
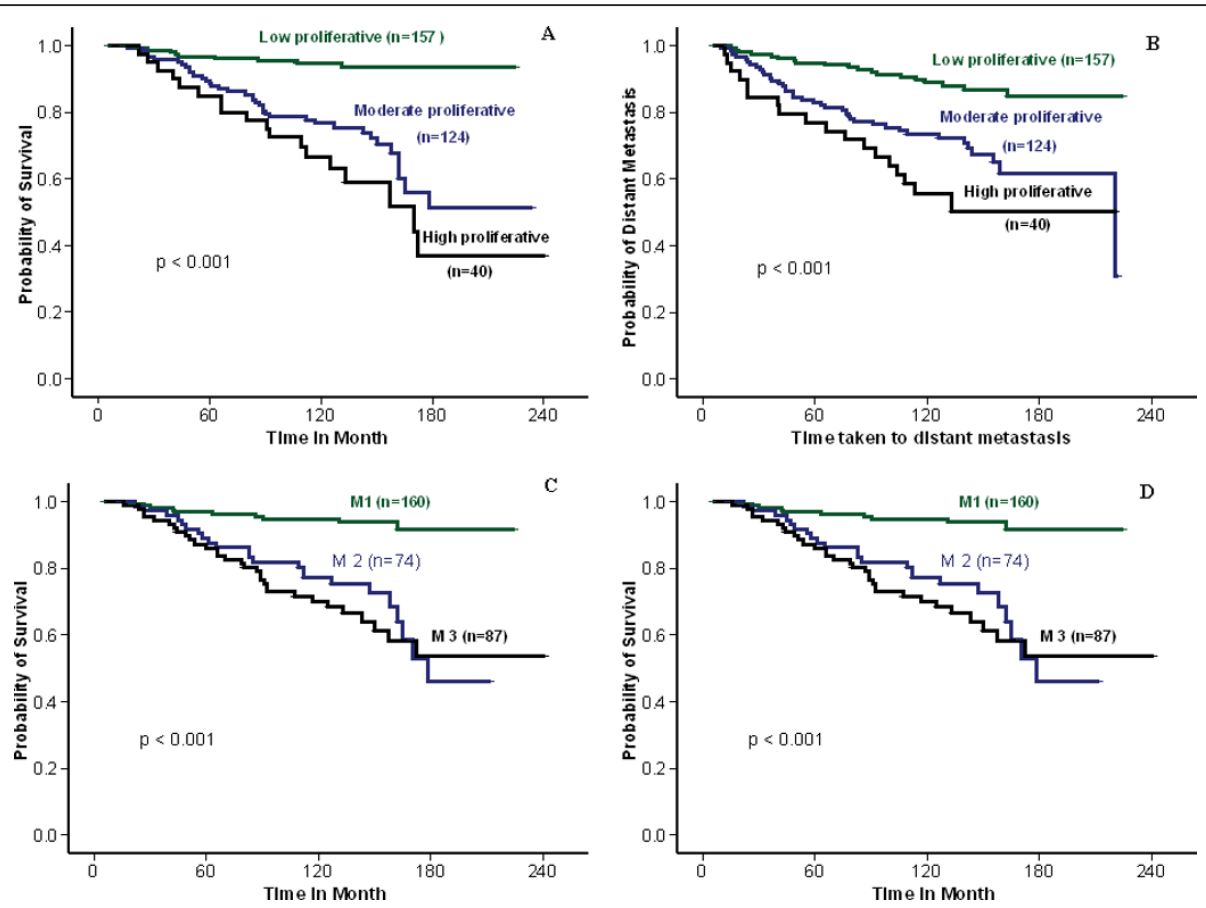

Figure 3 Kaplan-Meier survival plot for luminal BC training set using Ki-67LI and MS. (a) Breast cancer-specific survival (BCSS). (b) Metastasis-free survival at 10\% and 50\% Ki-67LI cut-off point. (c, d) BCSS and DMFS for mitosis-frequency scores. 


\begin{tabular}{|c|c|c|c|}
\hline & Luminal number (\%) & HER2 $^{+}$number $(\%)$ & TN number $(\%$ \\
\hline Total $^{a}$ & 967 (69.9) & $193(13.6)$ & $240(16.5)$ \\
\hline \multicolumn{4}{|l|}{ Mitosis scores } \\
\hline 1 & $318(48.8)$ & $16(12.5)$ & $4(2.5)$ \\
\hline 2 & $143(22)$ & $29(22.7)$ & $8(5)$ \\
\hline 3 & $190(29.2)$ & $83(64.8)$ & $148(92.5)$ \\
\hline Training set $^{\mathrm{b}}$ & $316(33)$ & $65(33)$ & 80 (33\%) \\
\hline Validation set ${ }^{\mathrm{b}}$ & $651(67)$ & $128(67)$ & $160(67)$ \\
\hline \multicolumn{4}{|l|}{ Ki-67LI in the validation sets } \\
\hline Ki-67 mean (SD) & $22(24.6)$ & $41.5(27.4)$ & $64.5(32)$ \\
\hline Ki-67LI median (range) & $11(0-98)$ & $39.5(0-97)$ & $77(1-98)$ \\
\hline Ki-67LI Cut-off & 10 & 70 & - \\
\hline
\end{tabular}

${ }^{a}$ This percentage is relative to the whole patients' series (that is, 1,457 cases). ${ }^{\text {b}}$ This percentage is relative to number of cases within the same class. Using $10 \%$ and $50 \% \mathrm{Ki}-67 \mathrm{LI}$ cut offs divided the luminal class into low (46.9\%), moderate (41.6\%), and high (11.5\%) proliferation subgroups, respectively. Ki-67LI cut-offs were generated by using X-tile software in the training sets.

provides valuable prognostic information and can subclassify luminal ( $\mathrm{HR}^{+}$tumors) into prognostically distinct subclasses. Therefore, in the current study, we used a well-characterized series of operable invasive $\mathrm{BC}$ to assess the prognostic significance of Ki-67LI with regard to $\mathrm{BC}$ molecular classes compared with that provided by the routinely assessed MS and addressed some technical issues for use in routine practice in assessing tumor proliferation.

The distributions of Ki-67LI values in this series (mean and median) were consistent with those found in previous studies [29,33], and have a significant correlation with MKI67 gene transcript and MS. Consis-tent with the results of GEP studies [2], the majority of HER2 ${ }^{+}$and TN tumors showed high proliferative activity in terms of high Ki-67LI and high MS, whereas up to half of luminal BCs were of low MS and showed low Ki-67LI.

In luminal $\mathrm{BC}$, proliferation assays using MS and $\mathrm{Ki}-$ 67LI identified subdivisions with statistically different patient outcomes. In this group, both MS and Ki-67LI retained their significant and independent association with outcome and identified three subclasses; one (low-
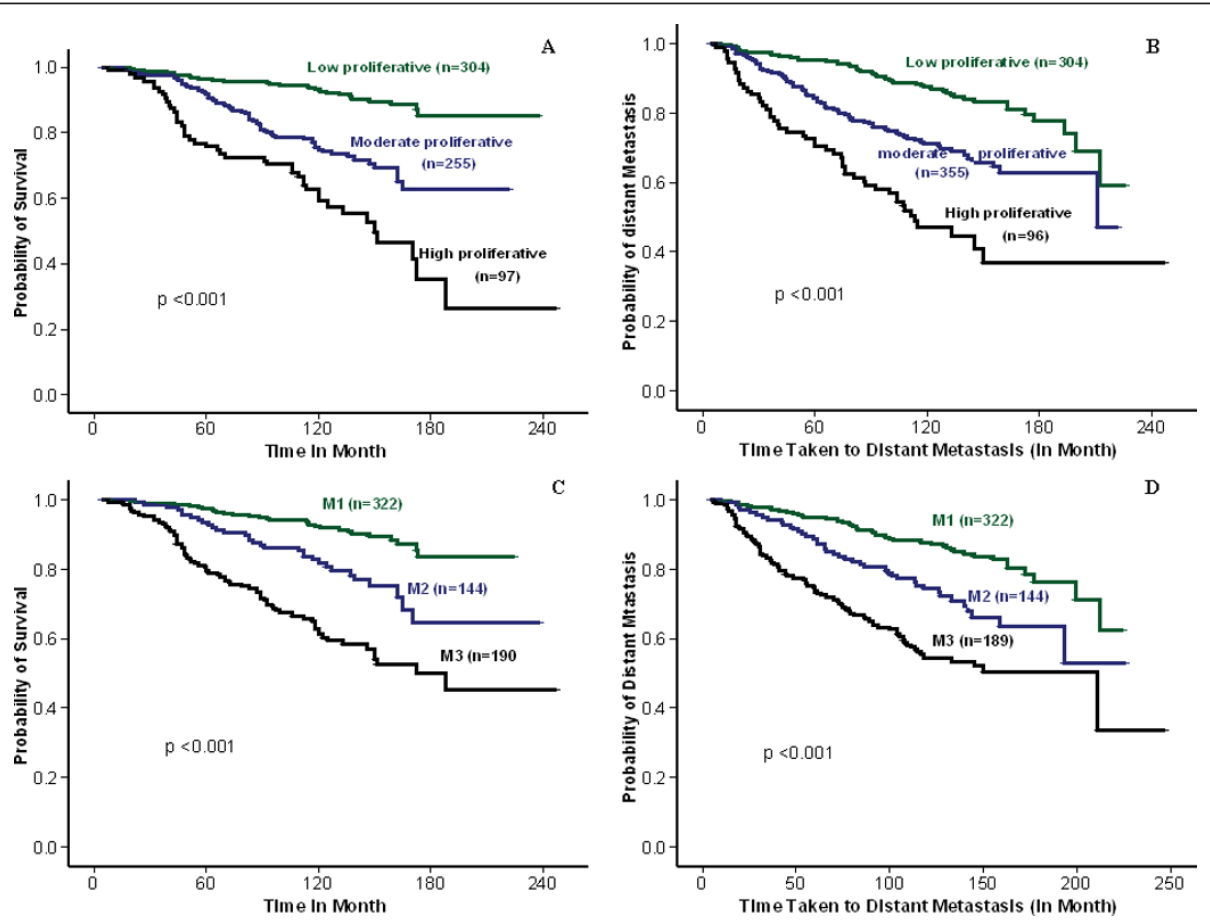

Figure 4 Kaplan-Meier survival plot for luminal BC validation set using Ki-67LI and MS. (a) Breast cancer-specific survival (BCSS) and (b) metastasis-free survival at 10\% and 50\% Ki-67LI cut-off point. (c, d) BCSS and DMFS for mitosis frequency scores (by using the validation set only). 
Table 5 Cox proportional hazards analysis for predictors of BCSS and DMFS in luminal BC valida-tion set: effect of Ki67LI, MS, tumor grade, nodal stage, tumor size, and adjuvant therapy

\begin{tabular}{|c|c|c|c|c|}
\hline \multirow[t]{3}{*}{ Variables } & \multicolumn{4}{|c|}{ Luminal BC } \\
\hline & \multicolumn{2}{|l|}{ BCSS } & \multicolumn{2}{|l|}{ DMFS } \\
\hline & $P$ value & HR $(95 \% \mathrm{Cl})$ & $P$ value & HR $(95 \% \mathrm{Cl})$ \\
\hline Ki-67LI & 0.019 & & 0.031 & \\
\hline \multicolumn{5}{|l|}{ Low } \\
\hline Moderate & 0.028 & $1.945(1.076-3.513)$ & 0.258 & $1.319(0.816-2.132)$ \\
\hline High & 0.005 & $2.679(1.347-5.330)$ & 0.013 & $2.097(1.171-3.754)$ \\
\hline Mitosis scores & 0.028 & & 0.015 & \\
\hline \multicolumn{5}{|l|}{1} \\
\hline 2 & 0.043 & $1.403(0.723-2.723)$ & 0.055 & $1.228(0.801-2.002)$ \\
\hline 3 & 0.033 & $2.096(0.938-4.687)$ & 0.018 & $1.854(0.919-3.741)$ \\
\hline Tumor grade & 0.022 & & 0.024 & \\
\hline \multicolumn{5}{|l|}{1} \\
\hline 2 & 0.016 & $1.379(0.647-2.938)$ & 0.041 & $1.604(0.878-2.930)$ \\
\hline 3 & 0.014 & $1.595(0.621-4.096)$ & 0.017 & $1.566(0.909-3.459)$ \\
\hline Nodal stage & 0.001 & & 0.001 & \\
\hline \multicolumn{5}{|l|}{ Node negative } \\
\hline 1 to 3 positive LN & 0.001 & $1.969(1.331-2.913)$ & 0.003 & $1.839(0.297-2.607)$ \\
\hline$\geq 4$ positive $\mathrm{LN}$ & 0.002 & $3.498(2.069-5.915)$ & 0.005 & $3.330(2.070-5.358)$ \\
\hline Tumor size & 0.221 & $1.262(0.869-0.834)$ & 0.019 & $1.492(1.067-2.087)$ \\
\hline Endocrine therapy (No/Yes) & 0.378 & $0.553(0.324-0.499)$ & 0.961 & $0.998(0.904-1.101)$ \\
\hline Chemotherapy (No/Yes) & 0.030 & $0.768(0.451-0.309)$ & 0.061 & $0.636(0.397-1.021)$ \\
\hline
\end{tabular}

BCSS, Breast cancer-specific survival; DMFS, distant metastasis-free survival; MS, mitosis score.

proliferative group) associated with excellent prognosis where adjuvant chemotherapy is unlikely to provide benefit and could potentially be withheld, and one class (high-proliferative group) with a worse prognosis akin to HER2 $^{+}$tumors trastuzumab (Herceptin)-naïve patients) that may be an appropriate subclass likely to benefit from chemotherapy. These findings confirm the prognostic relevance of routinely assessed MS in the luminal class, as previously reported in $\mathrm{BC}[1,7,8]$. It is, however, important to recognize that our results relating to MS

Table 6 Cox proportional hazards analysis for predictors of BCSS in luminal BC validation set: effect of Ki-67LI, MS, tumor grade, HER2 status, PR status, and adjuvant therapy

\begin{tabular}{|c|c|c|c|c|}
\hline \multirow[t]{3}{*}{ Variables } & \multicolumn{4}{|c|}{ Luminal BC } \\
\hline & \multicolumn{2}{|l|}{ BCSS } & \multicolumn{2}{|l|}{ DMFS } \\
\hline & $P$ value & $\mathrm{HR}(95 \% \mathrm{CI})$ & $P$ value & $\mathrm{HR}(95 \% \mathrm{Cl})$ \\
\hline Ki-67LI & 0.006 & & 0.003 & \\
\hline \multicolumn{5}{|l|}{ Low } \\
\hline Moderate & 0.020 & $2.016(1.118-3.636)$ & 0.211 & $1.359(0.840-2.198)$ \\
\hline High & 0.002 & $3.002(1.522-5.923)$ & 0.002 & $2.504(1.410-4.448)$ \\
\hline Tumor grade & 0.031 & & 0.021 & \\
\hline \multicolumn{5}{|l|}{1} \\
\hline 2 & 0.018 & $1.696(0.783-3.672)$ & 0.055 & $1.817(0.987-3.346)$ \\
\hline 3 & 0.023 & $1.736(0.634-4.753)$ & 0.011 & $1.556(0.986-3.659)$ \\
\hline HER2 status & 0.021 & $1.528(1.022-2.385)$ & 0.042 & $1.263(0.982-2.746)$ \\
\hline Mitosis scores & 0.018 & & 0.044 & \\
\hline \multicolumn{5}{|l|}{1} \\
\hline 2 & 0.043 & $1.267(0.651-2.466)$ & 0.013 & $1.292(0.742-2.257)$ \\
\hline 3 & 0.086 & $2.113(0.899-4.967)$ & 0.017 & $1.877(0.881-3.999)$ \\
\hline PR status & 0.030 & $0.635(0.422-0.956)$ & 0.064 & $0.701(0.481-1.021)$ \\
\hline Endocrine therapy (No/Yes) & 0.886 & $0.992(0.890-1.106)$ & 0.314 & $1.049(0.955-1.152)$ \\
\hline Chemotherapy (No/Yes) & 0.332 & $0.768(0.451-0.309)$ & 0.640 & $0.893(0.557-1.432)$ \\
\hline
\end{tabular}



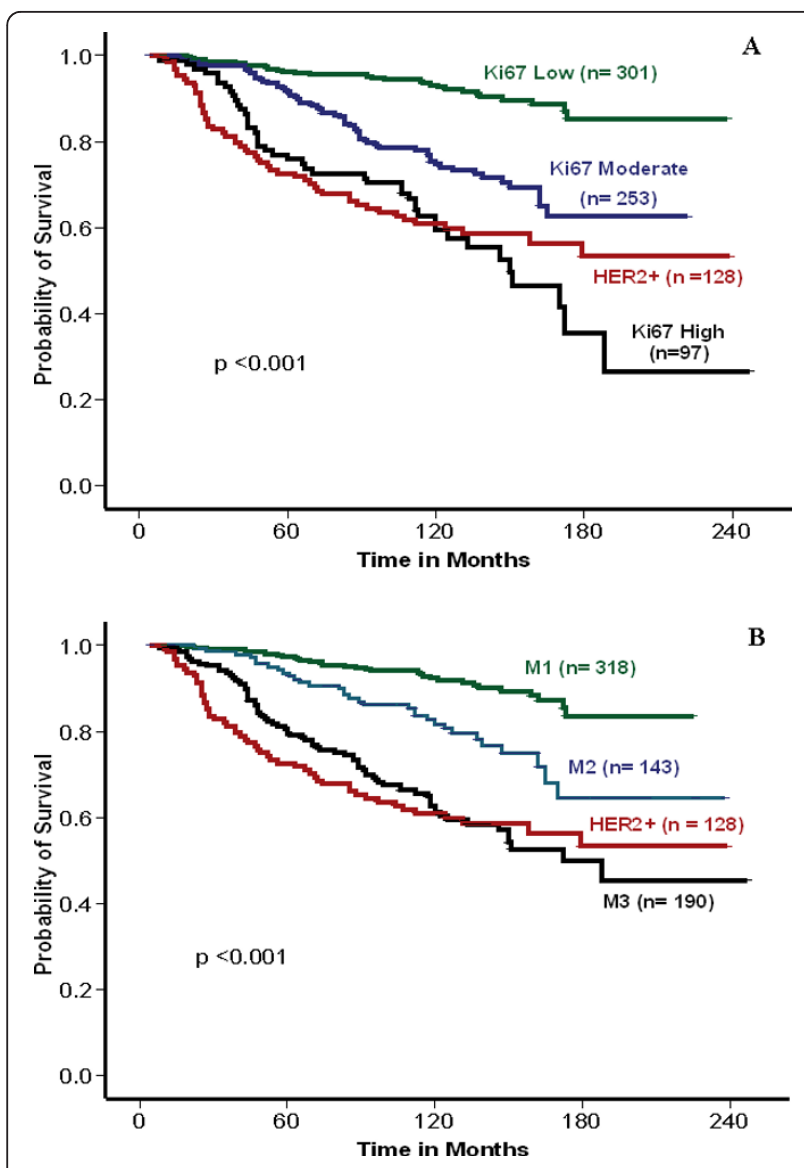

Figure 5 Kaplan-Meier survival plot of luminal tumors showing association between HER2 status and proliferation. (Ki-67LI, a, and $M S, \mathbf{b})$ and $B C S S(L R=88 ; P<0.0001 ; H R, 1.683 ; 95 \% \mathrm{Cl}, 1.492$ to 1.898 , and $L R, 90.239 ; P<0.0001 ; H R, 1.749 ; 95 \% \mathrm{Cl}, 1.543$ to 1.982 , respectively; validation set only). Number of patients at risk is shown above the curves. are based on optimized and standardized methods for tissue handling, fixation, and preparation [21]. Suboptimal tissue fixation has been demonstrated to affect adversely the ability to assess mitotic frequency, resulting in a systematic downgrading of cases [34-36]. Critical evaluation of these issues with recommendations for good practice has been provided by professional organizations. Significant improvements in the consistency of assessment of mitotic counts and hence histologic grading have been observed on a national basis in the United Kingdom through publication of guidelines with linked educational activity and associated external quality assurance [34]. However, it is worth mentioning that the prognostic information obtained by Ki-67LI in luminal tumors is equivalent to or even greater (in terms of $\mathrm{HR}$ ) than that provided by MS alone and than that provided by histologic grade or HER2 or PR status.

Different authorities have highlighted the prognostic significance of Ki-67LI in luminal BC, with emphasis on its ability to stratify patients into low-risk and high-risk populations. Although, in these studies, luminal BCs were subdivided into distinct subgroups, the optimal cut-off point remains nonstandardized, with most studies using a single, usually the median, cut-off point; dividing these tumors into two subgroups [16]. In this study, two cut-offs for Ki-67LI (10\% and 50\%) were identified as derived from associations with patient outcome in luminal tumors, which is the largest class of $\mathrm{BC}$; three subdivisions with significantly different outcomes with adequate numbers of cases within each subgroup. In this study, the proliferative activity assessed by using Ki-67LI was compared with mitotic counts that were scored in routine practice by using full-face sections (one to four sections per tumor). Ki-67 LI was

Table 7 Ten-year survival rates of hormone receptors positive $\left(\mathrm{ER}^{+}\right.$and/or $\mathrm{PR}^{+}$)/luminal class (including $\mathrm{HER2}^{+}$cases) based on proliferation assay (Ki-67LI and mitotic scores) and HER2 status

\begin{tabular}{|c|c|c|c|c|c|c|}
\hline \multirow[t]{2}{*}{ Variable } & \multicolumn{3}{|l|}{ BCSS } & \multicolumn{3}{|l|}{ DMFS } \\
\hline & $\begin{array}{l}\text { Number exposed to } \\
\text { risk }\end{array}$ & $\begin{array}{l}\text { Number of } \\
\text { events }\end{array}$ & $\begin{array}{l}\text { Proportion } \\
\text { surviving }\end{array}$ & $\begin{array}{l}\text { Number exposed to } \\
\text { risk }\end{array}$ & $\begin{array}{l}\text { Number of } \\
\text { events }\end{array}$ & $\begin{array}{l}\text { Proportion } \\
\text { surviving }\end{array}$ \\
\hline \multicolumn{7}{|l|}{ Ki-67LI } \\
\hline Low & 295 & 28 & $90.5 \%$ & 295 & 46 & $84.4 \%$ \\
\hline Moderate & 250 & 68 & $72.8 \%$ & 249 & 77 & $69.7 \%$ \\
\hline High & 95 & 43 & $54.7 \%$ & 94 & 50 & $46.8 \%$ \\
\hline \multicolumn{7}{|l|}{ Mitotic score } \\
\hline 1 & 324 & 39 & $88 \%$ & 324 & 58 & $82 \%$ \\
\hline 2 & 156 & 36 & $77 \%$ & 155 & 46 & $70.3 \%$ \\
\hline 3 & 226 & 93 & $58.8 \%$ & 225 & 101 & $55 \%$ \\
\hline \multicolumn{7}{|l|}{ HER2 status } \\
\hline Negative & 622 & 136 & $78.1 \%$ & 620 & 170 & $72.5 \%$ \\
\hline Positive & 66 & 29 & $56 \%$ & 66 & 32 & $51.5 \%$ \\
\hline
\end{tabular}

BCSS, Breast cancer-specific survival; DMFS, distant metastasis-free survival. 
assessed by using full-face sections to avoid missing the hot spot and to provide data that can be used in routine practice rather than TMA, which is currently a research tool. Although some research studies of Ki-67LI have reported correlation between Ki-67LI assessed on TMA or needle-core biopsy [37] and that assessed on full-face sections, these correlations are not absolute, and discrepant cases exist. The results of the current study support other studies that demonstrated that Ki-67LI should be assessed in the most active areas (hot spots), a method that has also been used and validated in the assessment of mitotic counts [21].

The majority of HER2 ${ }^{+}$and TN tumors are known to be poorly differentiated and highly proliferative [2]. No association between MS and outcome could be identified in either $\mathrm{HER}_{2}{ }^{+}$or TN classes. None of the previously reported $\mathrm{Ki}-67 \mathrm{LI}$ cut-off points was able to stratify HER2 ${ }^{+}$or $\mathrm{TN}$ tumors into clinically relevant subclasses. Although the high Ki-67LI cut-off generated in $\mathrm{HER}_{2}{ }^{+}$and $\mathrm{TN}$ training sets appeared to stratify these tumors into proliferative subgroups based on outcome, no association with survival was identified in the validation sets. These findings could be explained by the small number of cases in these molecular classes after splitting them into training and validation sets or by their high proliferation rate, which limits the ability of a proliferation marker to identify clinically distinct subclasses.

The number of sections from each case required to assess Ki-67LI reliably in a clinical laboratory setting also was addressed. The results obtained from each of four sections assessed per tumor showed a high level of concordance, indicating that using a single FFS/case appears appropriate and representative.

It is important, however, to mention that in the current study, outcome was assessed in a context in which the treatment given may not be homogeneous, and indeed, in some cases, the parameter being addressed (mitotic score as a grading component) may have affected the original systemic treatment decision. This may limit the ability of the prognostic analyses in making assertions that either mitotic counts or Ki-67LI can identify a group in which chemotherapy could be withheld.

\section{Conclusion}

In conclusion, proliferation assessment by using Ki-67LI and MS can distinguish subgroups of patients with luminal/ $\mathrm{HR}^{+} \mathrm{BC}$ with significantly different clinical outcomes. Overall, both showed comparable results, with Ki-67LI having a marginal advantage in terms of patient-cohort separation. Neither MS nor Ki-67LI has additional prognostic value in HER $2^{+}$and TNBC. This study emphasises the importance of determination of appropriate clinically relevant cut points for Ki-67LI and demonstrates that sufficient IHC assessment of Ki-67LI can be achieved by using a single FFS. This method could provide a cost-effective method for prognostic subclassification of luminal/ $\mathrm{HR}^{+} \mathrm{BC}$ in routine clinical practice.

\section{Abbreviations}

$\mathrm{CISH}$ : chromomeric in situ hybridization; ER: estrogen receptor; FFPE: formalin-fixed paraffin-embedded; HER2: human epidermal growth factor receptor 2; IHC: immunohistochemistry; Ki-67LI: Ki-67 labeling index; MSs: mitotic frequency scores; PR: progesterone receptor; $\mathrm{TN}$ : triple negative; TNnon-B: triple-negative non-basal.

\section{Acknowledgements}

We acknowledge the support of the University of Nottingham and Nottingham University Hospitals Trust in funding EA Rakha and IO Ellis. We thank the Ministry of Higher Education (Egypt) for funding MA Aleskandarany, and the Breast Cancer Campaign for funding AR Green.

\section{Author details}

'Department of Histopathology, School of Molecular Medical Sciences, Queens Medical Centre, University of Nottingham and Nottingham University Hospitals NHS Trust, Nottingham, NG7 2UH, UK. Pathology Department, Faculty of Medicine, Menoufia University, Shebin El-Kom, Menoufia Governorate, Egypt. ${ }^{3}$ Occupational Health, School of Molecular Medical Sciences, Queens Medical Centre, University of Nottingham and Nottingham University Hospitals NHS Trust, Nottingham, NG7 2UH, UK ${ }^{4}$ Breakthrough Breast Cancer Research Centre, Institute of Cancer Research, 237 Fulham Road, London, SW3 6JB, UK.

\section{Authors' contributions}

MA performed the practical work, performed the statistical analysis, and drafted the manuscript. EAR conceived and designed the project, participated in the statistics and in writing the manuscript. $A A B, F B$, and $A R G$ participated in the practical work and contributed to the manuscript. IOE and JSR-F contributed to the project design and to the manuscript. All authors read and approved the final manuscript.

\section{Competing interests}

The authors declare that they have no competing interests.

Received: 29 October 2010 Revised: 13 November 2011

Accepted: 6 January 2012 Published: 6 January 2012

\section{References}

1. Daidone $M G$, Silvestrini R: Prognostic and predictive role of proliferation indices in adjuvant therapy of breast cancer. $J$ Natl Cancer Inst Monogr 2001, 30:27-35

2. Wirapati $P$, Sotiriou C, Kunkel S, Farmer P, Pradervand S, Haibe-Kains B, Desmedt C, Ignatiadis M, Sengstag T, Schütz F, Goldstein DR, Piccart M, Delorenzi M: Meta-analysis of gene expression profiles in breast cancer: toward a unified understanding of breast cancer subtyping and prognosis signatures. Breast Cancer Res 2008, 10:R65

3. Weigelt B, Baehner FL, Reis-Filho JS: The contribution of gene expression profiling to breast cancer classification, prognostication and prediction: a retrospective of the last decade. J Pathol 2010, 220:263-80.

4. Paik S, Shak S, Tang G, Kim C, Baker J, Cronin M, Baehner FL, Walker MG, Watson D, Park T, Hiller W, Fisher ER, Wickerham DL, Bryant J, Wolmark N: A multigene assay to predict recurrence of tamoxifen-treated, nodenegative breast cancer. N Engl J Med 2004, 351:2817-26.

5. Sotiriou C, Wirapati $P$, Loi S, Harris A, Fox S, Smeds J, Nordgren H, Farmer $P$, Praz V, Haibe-Kains B, Desmedt C, Larsimont D, Cardoso F, Peterse H, Nuyten D, Buyse M, Van de Vijver MJ, Bergh J, Piccart M, Delorenzi M: Gene expression profiling in breast cancer: understanding the molecular basis of histologic grade to improve prognosis. J Natl Cancer Inst 2006, 98:262-72.

6. Ivshina AV, George J, Senko O, Mow B, Putti TC, Smeds J, Lindahl T, Pawitan Y, Hall P, Nordgren H, Wong JE, Liu ET, Bergh J, Kuznetsov VA, 
Miller LD: Genetic reclassification of histologic grade delineates new clinical subtypes of breast cancer. Cancer Res 2006, 66:10292-301.

7. Beresford MJ, Wilson GD, Makris A: Measuring proliferation in breast cancer: practicalities and applications. Breast Cancer Res 2006, 8:216.

8. Rakha EA, El-Sayed ME, Lee AH, Elston CW, Grainge MJ, Hodi Z, Blamey RW, Ellis IO: Prognostic significance of Nottingham histologic grade in invasive breast carcinoma. J Clin Oncol 2008, 26:3153-8.

9. Johnson HA, Bond VP: A method of labeling tissues with tritiated thymidine in vitro and its use in comparing rates of cell proliferation in duct epithelium, fibroadenoma, and carcinoma of human breast. Cancer 1961, 14:639-43.

10. van Diest PJ, van der Wall E, Baak JPA: Prognostic value of proliferation in invasive breast cancer: a review. J Clin Pathol 2004, 57:675-81.

11. Simpson JF, Gray R, Dressler LG, Cobau CD, Falkson Cl, Gilchrist KW, Pandya KJ, Page DL, Robert NJ: Prognostic value of histologic grade and proliferative activity in axillary node-positive breast cancer: results from the Eastern Cooperative Oncology Group Companion Study, EST 4189. J Clin Oncol 2000, 18:2059-69.

12. Medri L, Volpi A, Nanni O, Vecci AM, Mangia A, Schittulli F, Padovani F, Giunchi DC, Zito A, Amadori D, Paradiso A, Silvestrini R: Prognostic relevance of mitotic activity in patients with node-negative breast cancer. Mod Pathol 2003, 16:1067-75.

13. Colozza M, Azambuja E, Cardoso F, Sotiriou C, Larsimont D, Piccart MJ: Proliferative markers as prognostic and predictive tools in early breast cancer: where are we now? Ann Oncol 2005, 16:1723-39.

14. Viale G, Regan MM, Mastropasqua MG, Maffini F, Maiorano E, Colleoni M, Price KN, Golouh R, Perin T, Brown RW, Kovács A, Pillay K, Ohlschlegel C, Gusterson BA, Castiglione-Gertsch M, Gelber RD, Goldhirsch A, Coates AS, International Breast Cancer Study Group: Predictive value of tumor Ki-67 expression in two randomized trials of adjuvant chemoendocrine therapy for node-negative breast cancer. J Natl Cancer Inst 2008, 100:207-12.

15. Gerdes J, Li L, Schlueter C, Duchrow M, Wohlenberg C, Gerlach C, Stahmer I, Kloth S, Brandt E, Flad HD: Immunobiochemical and molecular biologic characterization of the cell proliferation-associated nuclear antigen that is defined by monoclonal antibody Ki-67. Am J Pathol 1991, 138:867-73.

16. Cheang MC, Chia SK, Voduc D, Gao D, Leung S, Snider J, Watson M, Davies S, Bernard PS, Parker JS, Perou CM, Ellis MJ, Nielsen TO: Ki67 index, HER2 status, and prognosis of patients with luminal B breast cancer. J Natl Cancer Inst 2009, 101:736-50.

17. Cuzick J, Dowsett M, Wale C, Salter J, Quinn E, Zabaglo L, Howell A, Buzdar A, Forbes JF: Prognostic value of a combined ER, PgR, Ki67, HER2 immunohistochemical $(\mathrm{IHC} 4)$ score and comparison with the GHI recurrence score: results from TransATAC. Cancer Res 2009, Suppl 24: 74.

18. Jacquemier J, Charafe-Jauffret E, Monville F, Esterni B, Extra JM, Houvenaeghel G, Xerri L, Bertucci F, Birnbaum D: Association of GATA3, P53, Ki67 status and vascular peritumoral invasion are strongly prognostic in luminal breast cancer. Breast Cancer Res 2009, 11:R23.

19. Weigelt B, Mackay A, A'Hern R, Natrajan R, Tan DS, Dowsett M, Ashworth A, Reis-Filho JS: Breast cancer molecular profiling with single sample predictors: a retrospective analysis. Lancet Oncol 2010, 11:339-49.

20. Elston CW, Ellis IO: Pathological prognostic factors in breast cancer: I. The value of histological grade in breast cancer: experience from a large study with long-term follow-up. Histopathology 1991, 19:403-10.

21. Ellis IO, Programmes NHSCS, Royal College of Pathologists, The Science C: Pathology Reporting of Breast Disease: a Joint Document Incorporating the Third Edition of the NHS Breast Screening Programme's Guidelines for Pathology Reporting in Breast Cancer Screening and the Second Edition of the Royal College of Pathologists' Minimum Dataset for Breast Cancer Histopathology. London: NHS Cancer Screening Programmes, Royal College of Pathologists; 2005.

22. Aleskandarany MA, Green AR, Rakha EA, Mohammed RA, Elsheikh $S E$, Powe DG, Paish EC, Macmillan RD, Chan S, Ahmed SI, Ellis IO: Growth fraction as a predictor of response to chemotherapy in node-negative breast cancer. Int J Cancer 2010, 126:1761-9.

23. Rakha EA, Elsheikh SE, Aleskandarany MA, Habashi HO, Green AR, Powe DG, El-Sayed ME, Benhasouna A, Brunet JS, Akslen LA, Evans AJ, Blamey R, ReisFilho JS, Foulkes WD, Ellis IO: Triple-negative breast cancer: distinguishing between basal and nonbasal subtypes. Clin Cancer Res 2009, 15:2302-10.
24. Rakha EA, El-Sayed ME, Green AR, Paish EC, Powe DG, Gee J, Nicholson Rl, Lee AH, Robertson JF, Ellis IO: Biologic and clinical characteristics of breast cancer with single hormone receptor positive phenotype. J Clin Oncol 2007, 25:4772-8.

25. Garcia-Caballero T, Grabau D, Green AR, Gregory J, Schad A, Kohlwes E, Ellis IO, Watts S, Mollerup J: Determination of HER2 amplification in primary breast cancer using dual-colour chromogenic in situ hybridization is comparable to fluorescence in situ hybridization: a European multicentre study involving 168 specimens. Histopathology 2010, 56:472-80.

26. Naderi A, Teschendorff AE, Barbosa-Morais NL, Pinder SE, Green AR, Powe DG, Robertson JF, Aparicio S, Ellis IO, Brenton JD, Caldas C: A geneexpression signature to predict survival in breast cancer across independent data sets. Oncogene 2007, 26:1507-16.

27. Cheang MC, VoduC D, Bajdik C, Leung S, McKinney S, Chia SK, Perou CM, Nielsen TO: Basal-like breast cancer defined by five biomarkers has superior prognostic value to triple-negative phenotype. Clin Cancer Res 2008, 14:1368-76.

28. Camp RL, Dolled-Filhart M, Rimm DL: X-tile: a new bio-informatics tool for biomarker assessment and outcome-based cut-point optimization. Clin Cancer Res 2004, 10:7252-9.

29. Spyratos F, Ferrero-Pous M, Trassard M, Hacene K, Phillips E, TubianaHulin M, Le Doussal V: Correlation between MIB-1 and other proliferation markers: clinical implications of the MIB-1 cutoff value. Cancer 2002, 94:2151-9.

30. Bottini A, Berruti A, Bersiga A, Brizzi MP, Bruzzi P, Aguggini S, Brunelli A, Bolsi G, Allevi G, Generali D, Betri E, Bertoli G, Alquati P, Dogliotti L: Relationship between tumour shrinkage and reduction in Ki67 expression after primary chemotherapy in human breast cancer. $\mathrm{Br} J$ Cancer 2001, 85:1106-12.

31. Carey LA, Perou CM, Livasy CA, Dressler LG, Cowan D, Conway K, Karaca G, Troester MA, Tse CK, Edmiston S, Deming SL, Geradts J, Cheang MC, Nielsen TO, Moorman PG, Earp HS, Millikan RC: Race, breast cancer subtypes, and survival in the Carolina Breast Cancer Study. JAMA 2006, 295:2492-502.

32. Tamimi RM, Baer HJ, Marotti J, Galan M, Galaburda L, Fu Y, Deitz AC, Connolly JL, Schnitt SJ, Colditz GA, Collins LC: Comparison of molecular phenotypes of ductal carcinoma in situ and invasive breast cancer. Breast Cancer Res 2008, 10:R67.

33. Jalava $\mathrm{P}$, Kuopio $T$, Juntti-Patinen $L$, Kotkansalo $T$, Kronqvist $P$, Collan Y: Ki67 immunohistochemistry: a valuable marker in prognostication but with a risk of misclassification: proliferation subgroups formed based on Ki67 immunoreactivity and standardized mitotic index. Histopathology 2006, 48:674-82.

34. Ellis IO, Coleman D, Wells C, Kodikara S, Paish EM, Moss S, Al-Sam S, Anderson N, Bobrow L, Buley I, Connolly CE, Dallimore NS, Hales S, Hanby A, Humphreys S, Knox F, Lowe J, Macartney J, Nash R, Parham D, Patnick J, Pinder SE, Quinn CM, Robertson AJ, Shrimankar J, Walker RA, Winder R: Impact of a national external quality assessment scheme for breast pathology in the UK. J Clin Pathol 2006, 59:138-45.

35. Bergers E, Jannink I, van Diest PI, Cuesta MA, Meyer S, van Mourik JC, Baak JP: The influence of fixation delay on mitotic activity and flow cytometric cell cycle variables. Hum Pathol 1997, 28:95-100.

36. Start RD, Cross SS, Smith JH: Assessment of specimen fixation in a surgical pathology service. J Clin Pathol 1992, 45:546-7.

37. Kwok TC, Rakha EA, Lee AH, Grainge M, Green AR, Ellis IO, Powe DG: Histological grading of breast cancer on needle core biopsy: the role of immunohistochemical assessment of proliferation. Histopathology 2010, 57:212-19.

\section{doi:10.1186/bcr3084}

Cite this article as: Aleskandarany et al:: Prognostic value of proliferation assay in the luminal, HER2-positive, and triple-negative biologic classes of breast cancer. Breast Cancer Research 2012 14:R3. 